\title{
ANALYSIS OF ORGANIC POLLUTANTS IN MICRO-PLASTICS
}

№ 101858

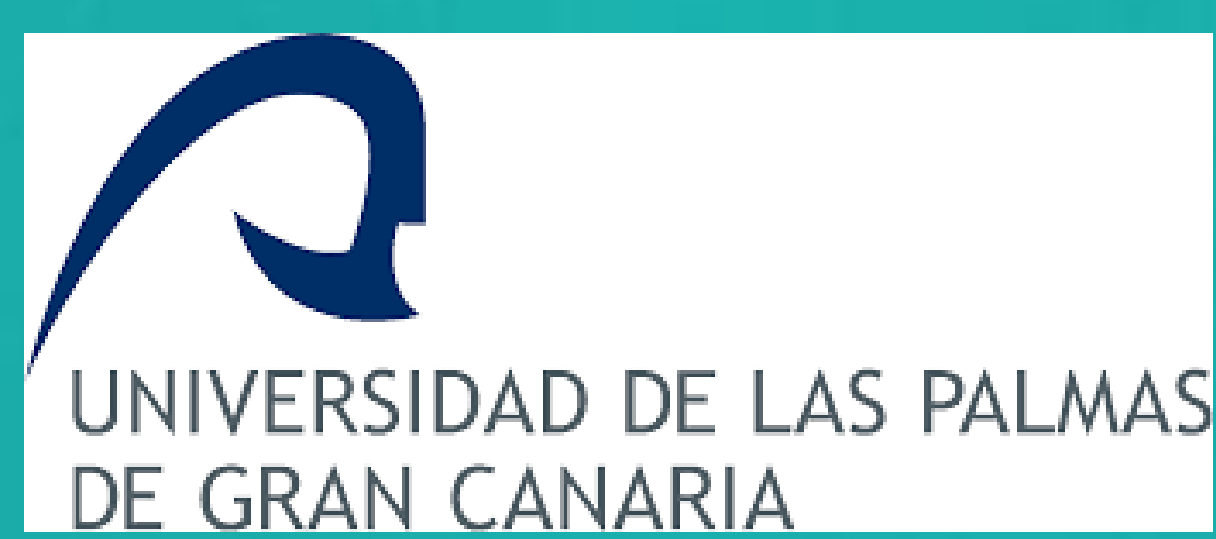

S. Santana-Viera, R. Guedes-Alonso, C. Afonso-Olivares, S. Montesdeoca-Esponda, M. E. Torres-Padrón, Z. Sosa-Ferrera, J.J. Santana-Rodríguez.

Instituto Universitario de Estudios Ambientales y Recursos Naturales (i-UNAT), Universidad de Las Palmas de Gran Canaria, 35017, Las Palmas de Gran Canaria, Spain, e-mail: sergio.viera@ulpgc.es

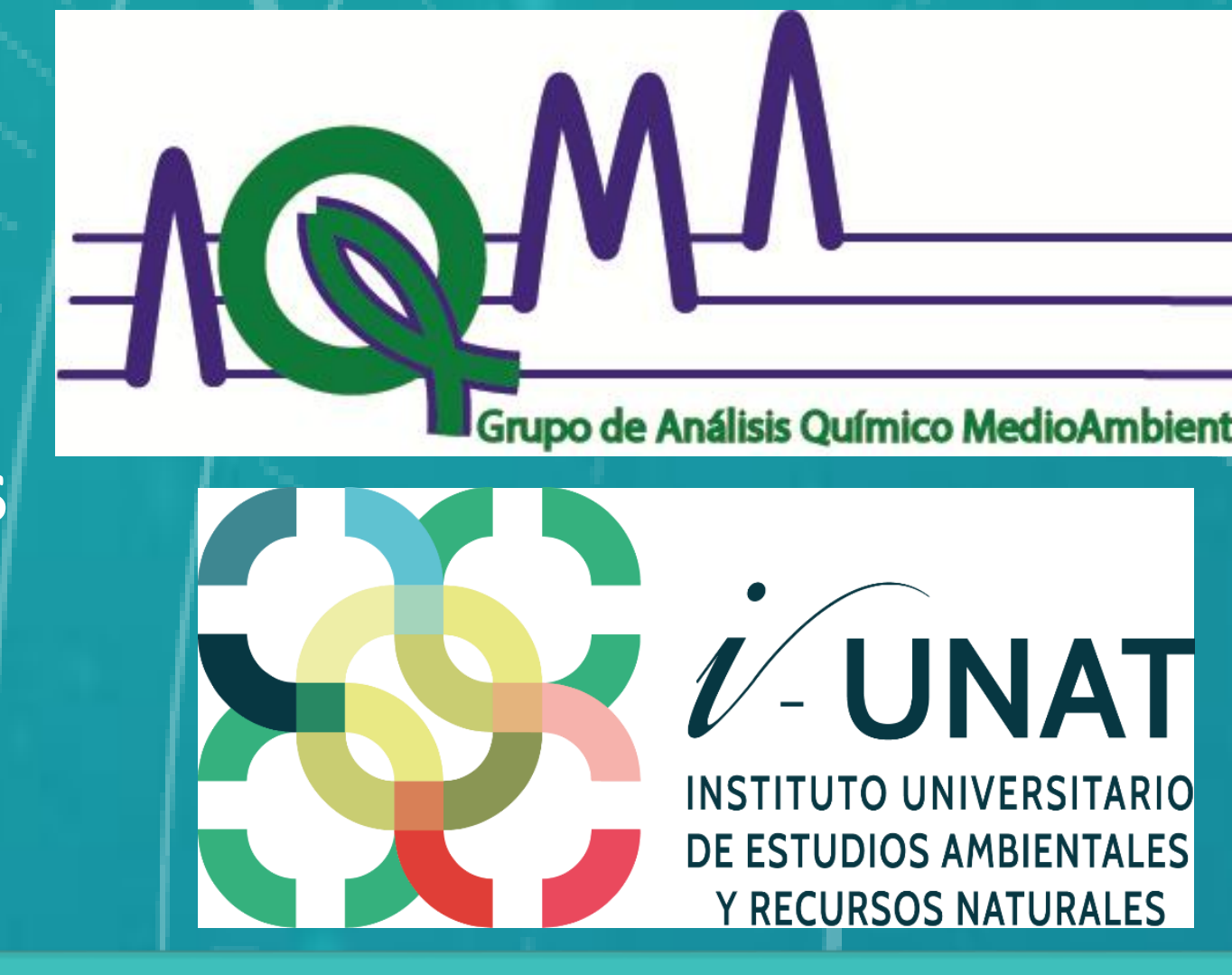

HOW ARE COMMONLY DETERMINED THE POLLUTANTS?

For the extraction of the pollutants, Soxhlet technique has been the most used [2-4] although it has also been utilised Accelerated Solvent Extractor [5].

For the determination of HOCs, also referred as Persistent Organic Pollutants (POPs), GC-MS have been the most employed technique. These pollutants include Polycyclic Aromatic Hydrocarbons (PAHs), Polychlorinated Biphenyls (PCBs), Dichlorodiphenyl-trichloroethanes (DDTs), Nonylphenols, (NPs), etc. [2, 3, 5]. Another techniques like GC-ECD have been used for the quantification of chlorinated benzenes (CBs) and hexachlorocyclohexanes (HCHs), or LC-FD for the determination of PAHs [1].

Only few researchers have used LC for the determination of pollutants in micro-plastics. Pharmaceuticals and Personal Care Products (PPCPs) have been determinated by LC-DAD previous extraction by SPE [6], concluding that micro-plastics might also act as an important carrier for the transport of PPCPs, especially for the hydrophobic ones.

\section{WHAT WE PROPOSE}

Our Research Group has experience in the determination of trace of organic compounds especially in emerging pollutants, in solid and liquid matrices [7-9]. We propose to transfer this experience to the field of micro-plastics and contaminants adsorbed to them.

Determination of micro-pollutants, including emerging contaminants, by UPLC-FD/DAD and UPLC-MS/MS

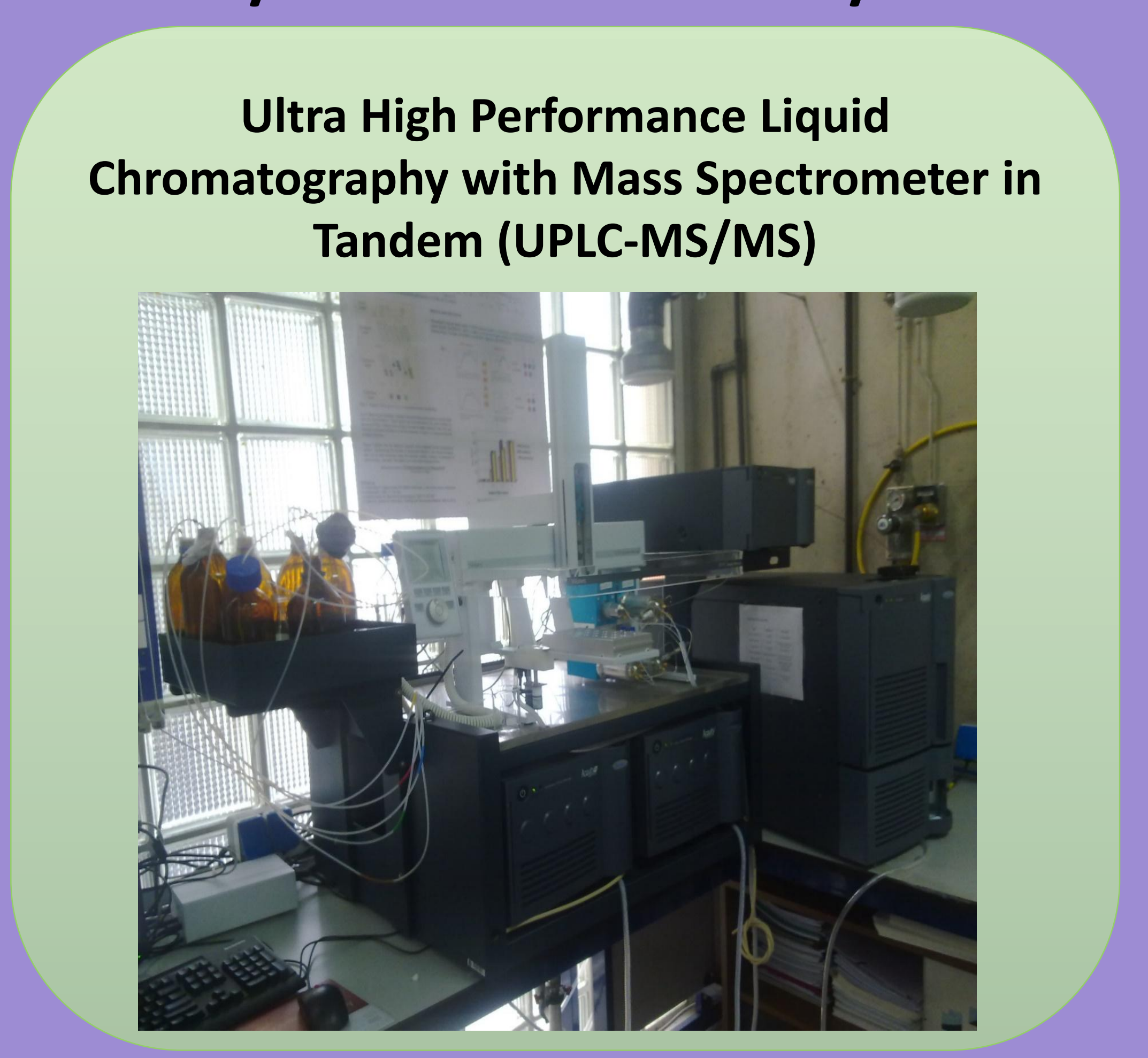

Ultra Perfomance Liquid Chromatography - Fluorescence Detector and Diodo Array Detector (UPLC-FD) (UPLC-DAD)

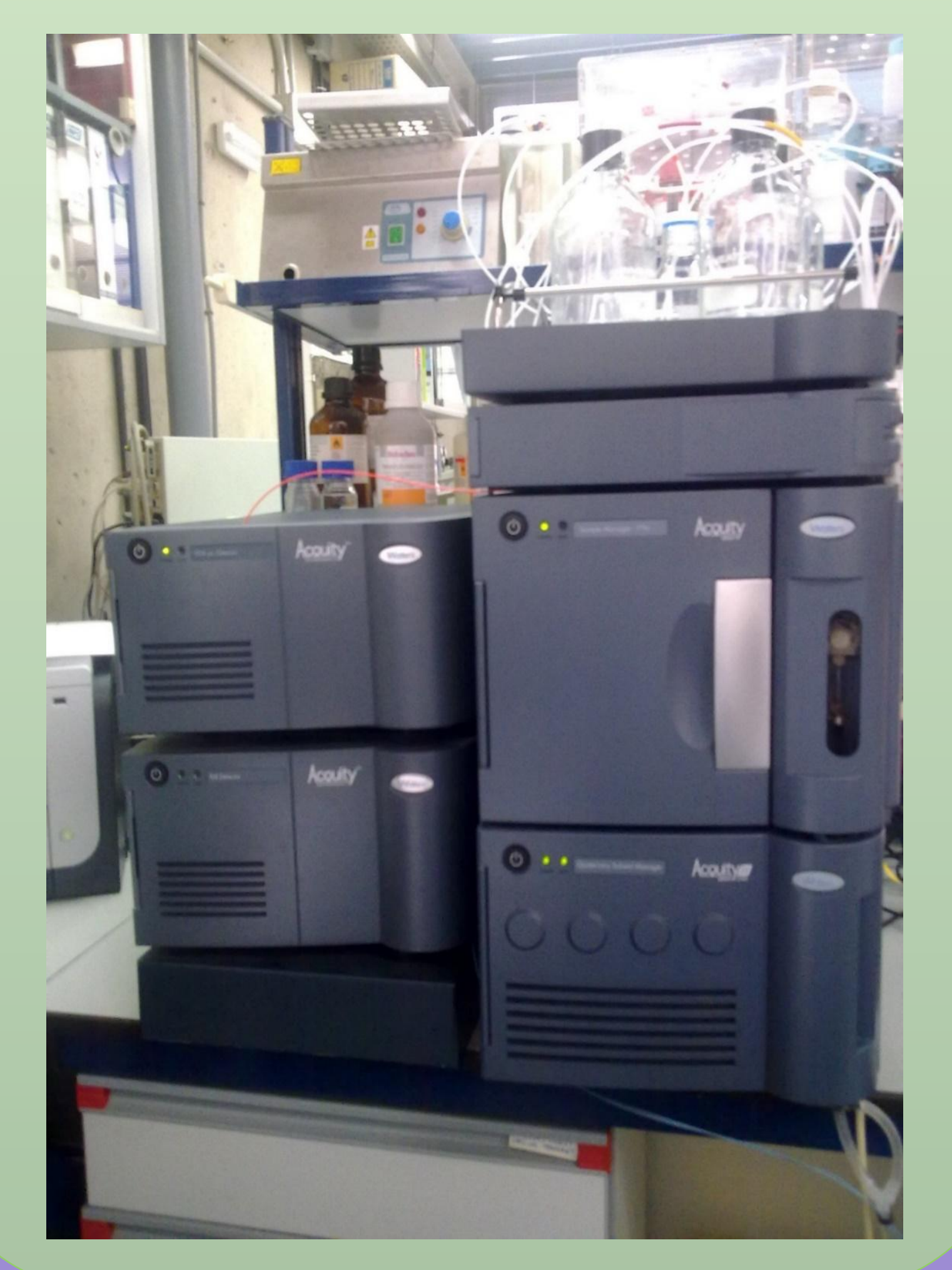

Extraction and preconcentration of liquid and solid samples by SPE and MAE

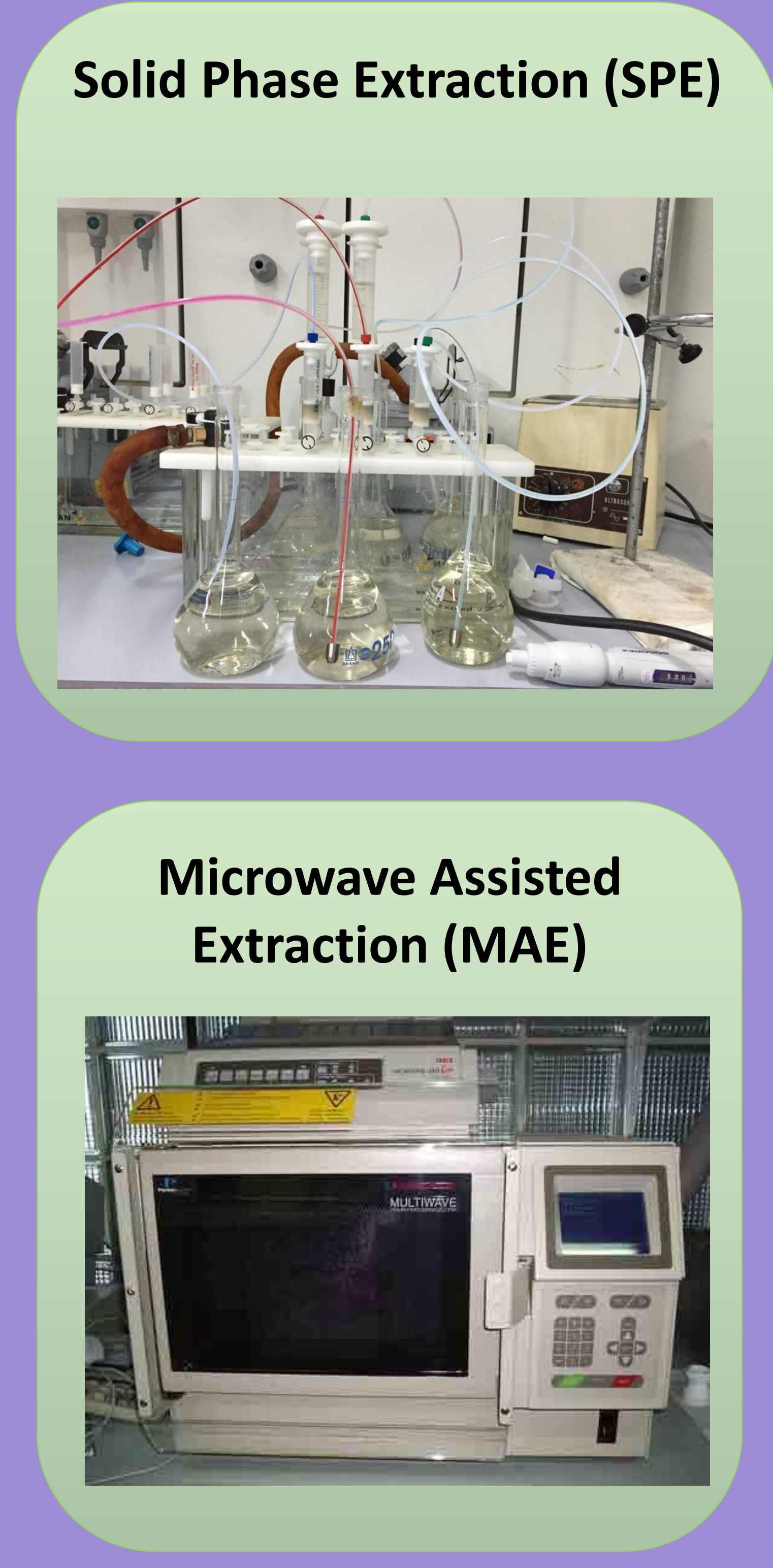

\section{REFERENCES}

1. H. Lee, W. J. Shim and J. H. Kwon. Science of the Total Environment 470-471 (2014) 1545-1552.

2. Y. Mato, T. Isobe, H. Takada, H. Kanehiro, C. Ohtake and T. Kaminuma. Environ. Sci. Technol. 35 (2001) 318-324.

3. L. M. Rios, C. Moore and P. R. Jones. Marine Pollution Bulletin 54 (2007) 1230-1237.

4. L. M. Rios, P. R. Jones, C.Moore and U. V. Narayan. J. Environ. Monit. 12 (2010) 2226-2236.

5. J.P.G.L. Frias, P. Sobral and A.M. Ferreira. Marine Pollution Bulletin 60 (2010) 1988-1992.

6. C. Wu, K. Zhang, X. Huang and J. Liu. Environ Sci Pollut Res. DOI 10.1007/s11356-016-6121-7.

7. S. Montesdeoca-Esponda, Z. Sosa-Ferrera, J. J. Santana-Rodríguez. Journal of Separation Science, 36(4) (2013) 781-788

8. T. Vega-Morales, Z. Sosa-Ferrera, J. J. Santana-Rodríguez. Water, Air and Soil Pollution, 224 (2013) 1486-1501.

9. R. Guedes-Alonso, Z. Sosa-Ferrera, J. J. Santana-Rodriguez. Analytical Methods, 7 (2015) 5996-6005. 